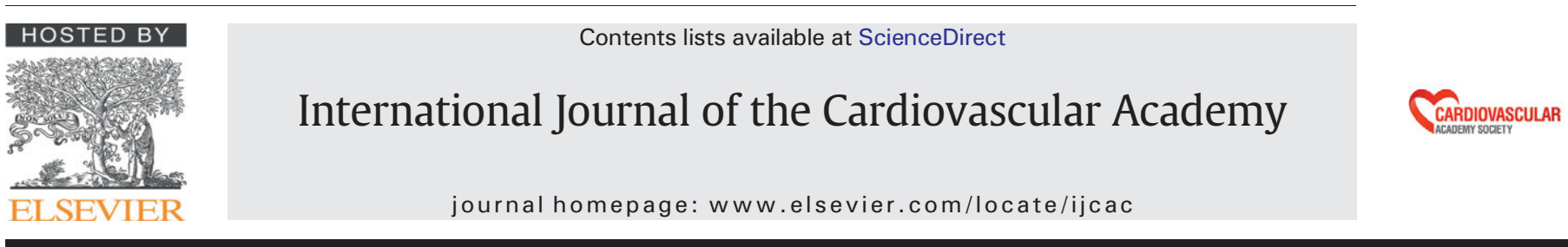

Review

\title{
Will NOACs become the new standard of care in anticoagulation therapy?
}

\author{
Ergene Oktay * \\ Department of Cardiology, Izmir Dokuz Eylul University Faculty of Medicine, Turkey
}

\section{A R T I C L E I N F O}

\section{Article history:}

Received 14 June 2015

Received in revised form 14 June 2015

Accepted 15 June 2015

Available online 21 August 2015

\section{Keywords:}

Atrial fibrillation

Warfarin

Oral anticoagulants

\begin{abstract}
A B S T R A C T
Atrial fibrillation is the most common cardiac arrhythmia in the general population, with a prevalence of 1-3\%, which increases with age, reaching $15 \%$ in elderly people. Prophylaxis of ischemic stroke with warfarin was the gold standard of medical management for many years. On the other hand heparin and warfarin was the main pharmacologic agents for the prophylaxis/treatment of venous thromboembolism. In the last 5 years warfarin is getting replaced by non-vitamin $\mathrm{K}$ antagonist oral anticoagulants at least partly. In this article it is attempted to foresee whether new oral anticoagulants will become the new standard of care in anticoagulation therapy.

(C) 2015 The Society of Cardiovascular Academy. Production and hosting by Elsevier B.V. All rights reserved. This is an open access article under the CC BY-NC-ND license (http://creativecommons.org/licenses/by-nc-nd/4.0/).
\end{abstract}

\section{Contents}

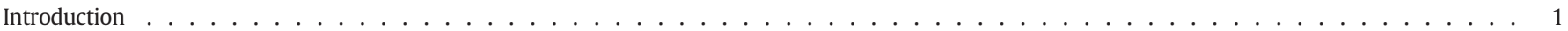

Discussion .. . . . . . . . . . . . . . . . . . . . . . . . . . . . . . . . . . . . . . . . 2

Will NOACs continue their upward trend and replace warfarin as the standard of care in upcoming years . . . . . . . . . . . . . . . . . . 2

Conclusion . . . . . . . . . . . . . . . . . . . . . . . . . . . . . . . . . . . . . 3

Disclosure statement . . . . . . . . . . . . . . . . . . . . . . . . . . . . . . . . . . . . . . . . . 3

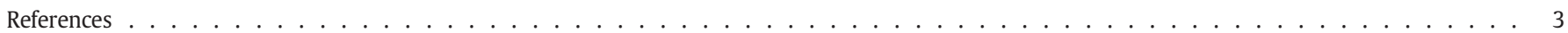

\section{Introduction}

In recent years, the development of novel oral anticoagulant agents (NOACs) such as dabigatran, rivaroxaban, apixaban and edoxaban has given health-care providers better treatment alternatives to aspirin, clopidogrel, heparin and warfarin, mainly for stroke prophylaxis in patients with non-valvular atrial fibrillation (NVAF), for prophylaxis/ treatment of venous thromboembolism (VTE) and also for the secondary prophylaxis of acute coronary syndromes (ACS).$^{1-3}$

Atrial fibrillation (AF) is the most frequently encountered dysrhythmia, which may lead to an increased risk of stroke. It may result in significant unfavorable health outcomes that include but are not limited to a 5-fold increased risk of stroke, hospitalization, impaired quality of life, and decreased work productivity. Stroke is a costly disease

\footnotetext{
* Department of Cardiology, Izmir Dokuz Eylul University Faculty of Medicine, Mithatpasa cad. no 1606 inciralti yerleskesi, 35340 Balcova, İzmir, Turkey. Tel.: +90232 41222 22; fax: + 902324129797

E-mail address: oktayergene@yahoo.com.tr.

Peer review under responsibility of The Society of Cardiovascular Academy.
}

from the perspective of individual, family, and society. AF-related stroke may lead to devastating consequences in terms of health and well-being of an individual. In patients with AF-related adverse events (e.g., thromboembolic infarctions), the outcomes are often poor, and may result in severe permanent neurologic deficit or mortality. ${ }^{4-8}$

Venous thromboembolism is the third most common cardiovascular condition after ACS and stroke. ${ }^{9}$ Although the exact incidence of VTE remains unknown, it is estimated that there are approximately 1 million cases in the United States per year, many of which represent recurrent disease.$^{10}$ Nearly two thirds of all VTE events result from hospitalization and approximately 300,000 of these patients die. ${ }^{11}$ Pulmonary embolism is the third most common cause of hospital-related death. ${ }^{12,13}$

The standard effective treatment of venous and arterial thromboembolism includes the use of unfractionated and low-molecular weight heparins as well as warfarin, which is associated with major disadvantages. In recent years, new anticoagulants have been developed in an attempt to overcome the known limitations of the established treatment approach and to provide improved therapies for the affected patients. $^{14-17}$

A meta-analysis published in 2007, of all currently available randomized trials that extend observations about the efficacy and safety 
of antithrombotic therapies for preventing stroke in patients who have AF showed that compared with the control, adjusted-dose warfarin and antiplatelet agents reduced stroke by $64 \%$ and $22 \%$ respectively. ${ }^{1}$ In 2013 a meta-analysis reported that new oral anticoagulants (NOACs) significantly reduced stroke or systemic embolic events by $19 \%$ compared with warfarin. New oral anticoagulants also significantly reduced all-cause mortality compared with warfarin. ${ }^{2}$

NOACs can be divided into two broad classes: (i) Direct thrombin inhibitors (dabigatran), which inhibit thrombin (Factor Ila), and (ii) Factor Xa inhibitors (rivaroxaban, apixaban, edoxaban), which inhibit factor Xa. Rivaroxaban, apixaban and edoxaban are oral, selective factor Xa inhibitors which block the active site of factor Xa, and these agents do not require a co-factor to exert their effects. The oral direct thrombin inhibitor, dabigatran, prevents the formation of thrombin through inhibition of the thrombin-dependent conversion of fibrinogen to fibrin. Dabigatran, rivaroxaban, apixaban and edoxaban inhibit both free and clot-bound fibrin, and indirectly inhibit thrombin-induced platelet aggregation. ${ }^{18,19}$

NOACs offer major pharmacological advantages over vitamin $\mathrm{K}$ antagonists (e.g., warfarin), including rapid onset/offset of action, few drug interactions, and predictable pharmacokinetics, which eliminates the requirement for regular coagulation monitoring associated with conventional anticoagulant therapy. ${ }^{18}$ From 2008, regulatory agencies in EU and US have approved several NOACs for specific indications based on the results obtained in clinical trials demonstrating efficacy and safety that are at least non-inferior, if not superior, compared to warfarin (for stroke prevention in AF as well as for treatment and secondary prevention of venous thromboembolism) or the injectable agent, low-molecular-weight heparin (Table 1).

The aim of this paper is to predict whether NOACs will become the new standard of care for the treatment of patients with NVAF and VTE. References are made to IMS (International Medical Statistics) Healthcare data to understand the trends in the global anticoagulation market.

Disclosure of global anticoagulant market sales was requested from IMS to investigate the development of the global anticoagulant market and to predict whether NOACs are likely to become the standard of care in their approved indications such as stroke prevention in NVAF and treatment of VTE. The claims in this paper are based on IMS Health global anticoagulant market sales data from 2008 to 2014.

\section{Discussion}

The decline in stroke mortality over the past decades has resulted from reduced stroke incidence and lower case fatality rates. The significant improvements in stroke outcomes are concurrent with cardiovascular risk factor control interventions. US health statistics shows that from 2001 to 2011, the relative rate of stroke death fell by 35\% and the actual number of stroke deaths declined by $21 \%{ }^{20}$ Stroke prevention is central to the appropriate control of hypertension, diabetes, high cholesterol, smoking cessation and management of atrial fibrillation. Until recently, the focus was to identify high-risk patients who would be given warfarin. Warfarin works best with high-quality anticoagulation (INR adjusted) control. High times in therapeutic range (>70\%) are associated with the best efficacy and safety of vitamin K antagonists, with low rates of stroke and bleeding.

Previously the only available anticoagulant was a vitamin K antagonist, but clinicians now have a choice and can fit the drug to the patient, and vice versa. In the last 5 years management of stroke prevention has changed with the availability of NOAC's. Thus, contemporary guidelines have focused on the initial identification of low-risk patients. Several NOACs now exist, offering similar (or better) effectiveness, safety, and convenience to the vitamin $\mathrm{K}$ antagonists. Dabigatran, rivaroxaban, apixaban and edoxaban is highly effective in reducing the risk of thromboembolic stroke with a more favorable safety profile. Although the bleeding risk is not negligible with NOAC's it is much better than anticoagulation with INR adjusted warfarin. NOACs have been released to the market in 2008, and the question of whether these agents will replace warfarin and heparins, which have been accepted as the gold standard for many years, is one that needs to be answered after a thorough evaluation of several aspects. Will NOACs continue their upward trend and replace warfarin as the standard of care in upcoming years?

In order to answer this question, the present paper will seek the answers to the following:

1. Are the new agents used in all indications for which standard therapy with warfarin and heparin can be used?

2. What are the benefits of NOACs over standard treatment in indications approved by the authorities?

3. To what extent are the physicians aware of these benefits and how much do they adapt to these advantages?

4. Are the new agents superior to standard therapy in terms of treatment costs?

5. Starting from the release of the new agents in the market, how has the dynamics changed for the global anticoagulant market?

\section{Will NOACs continue their upward trend and replace warfarin as the standard of care in upcoming years}

1. All of the pivotal trials comparing VKAs with NOACs in AF have enrolled patients with so-called NVAF, and excluded patients at particularly high risk of thromboembolism, such as those with AF accompanied by mitral stenosis or patients with mechanical prosthetic valves. The reasons for excluding these patients in trials evaluating NOACs included the possibility that the pathogenesis of thromboembolism may be substantially different from other types of $\mathrm{AF}^{21}$ In this context, it is not possible to use NOACs in patients with valve related conditions in light of the available data.

Table 1

Approved NOAC's in EU and US.

http://ec.europa.eu/health/documents/community-register/html/alfregister.htm. http://www.accessdata.fda.gov/scripts/cder/drugsatfda/index.cfm.

\begin{tabular}{|c|c|c|c|c|c|c|c|c|}
\hline \multirow[t]{2}{*}{ NOACs } & \multicolumn{2}{|c|}{$\begin{array}{l}\text { Prevention of venous thromboembolism in patients } \\
\text { undergoing hip/knee replacement surgery }\end{array}$} & \multicolumn{2}{|c|}{$\begin{array}{l}\text { Stroke prevention in } \\
\text { non-valvular atrial fibrillation }\end{array}$} & \multicolumn{2}{|c|}{$\begin{array}{l}\text { Treatment/secondary prophylaxis of deep } \\
\text { vein thrombosis and pulmonary embolism }\end{array}$} & \multicolumn{2}{|c|}{$\begin{array}{l}\text { Secondary prevention of acute } \\
\text { coronary syndromes }\end{array}$} \\
\hline & US & EU & US & EU & US & $\mathrm{EU}$ & US & $\mathrm{EU}$ \\
\hline Dabigatran & - & Mar '08 & Oct '10 & Aug '11 & June '14 & April '14 & - & - \\
\hline Rivaroxaban & July '11 & Sept '08 & Nov '11 & Dec '11 & Nov '12 & $\begin{array}{l}\text { Dec '11 (DVT) } \\
\text { Nov'12 (PE) }\end{array}$ & - & May '13 \\
\hline Apixaban & March '14 & May '11 & Dec '12 & Nov '12 & July '14 & Aug '14 & - & - \\
\hline Edoxaban & na* & na* & Jan '15 & - & Jan '15 & - & - & - \\
\hline
\end{tabular}

\footnotetext{
* Only in Japan, not in EU/US
} 
2. All of these NOACs evaluated for the indication of stroke prevention in patients with NVAF have shown non-inferiority compared to Vitamin K antagonists. ${ }^{22-24}$ All new generation oral anticoagulants have significantly decreased the risk of hemorrhagic stroke and intracranial bleeding, and they have not been associated with an apparent increase in major bleeding risk compared to warfarin. ${ }^{22-24}$ Consistent with the findings of the major studies, results of metaanalysis have demonstrated significantly decreased rates of stroke or systemic embolism and hemorrhagic stroke with these treatments compared to warfarin. ${ }^{25}$ However, because of the heterogeneity of different studies and the lack of head-to-head clinical trials with NOACs, one cannot draw a conclusion to say which of these agents is the best option. ${ }^{26}$

3. While it is not possible to exactly know to what extent physicians adopt the superiority that NOACs demonstrate in different therapeutic fields, investigating NOAC usage data in different countries may be informative. In this regard, market data may reflect that these agents are adopted at different levels in different parts of the world. Looking at the number of tablets patients use (standard units), it can be concluded that: While the use of NOACs is approximately $35 \%$ of that of the agents accepted as standard (warfarin + heparin) in US, it is around 15\% in "Emerging Markets" region, which also includes Turkey. ${ }^{27}$

4. Stroke leads to substantial financial burden on healthcare systems, as well as on patients, family, and society. The lifetime cost of an ischemic stroke was estimated to be over $\$ 90,000$ for an individual patient in 1990, and the American Heart Association estimated that the total national cost (direct plus indirect costs) of stroke in the United States exceeded $\$ 34$ billion in 2008 . $^{28,29}$

Treatment cost often poses a concern with NOACs. However, the total exact cost of strokes and the provision of anticoagulation monitoring is not completely understood and considered when assessing the cost impact of NOACs. Costs incurred by patient visits to anticoagulation monitoring clinics, and the cost of hospital admissions and other factors of managing the adverse effects of warfarin, are not always taken into account.

In 2013, Harrington et al. conducted a cost effectiveness study taking into consideration the aforementioned factors. Their study compared the cost effectiveness of warfarin to that of dabigatran, rivaroxaban and apixaban, which had been approved by authorities as of 2013 . The modeled population in this study was a hypothetical cohort of 70 -year old patients with NVAF, increased risk for stroke (CHADS2 $\geq 1$ ), renal creatinine clearance $\geq 50 \mathrm{~mL} / \mathrm{min}$, and no previous contraindications to anticoagulation. The study findings demonstrated that all of the new generation agents were cost-effective compared to warfarin. ${ }^{30}$

It may be predicted that growing data from such studies may result in positive contributions in favor of NOACs from the policy maker perspective; and in this regard, one may suggest that NOACs are candidates to replace warfarin in anticoagulation therapy.

5. When answering the question of whether NOACs may or may not replace the widely accepted gold standard therapy with warfarin and heparin for their respective indications in certain therapeutic fields, one should also consider how the dynamics of the market have changed since the introduction of NOACs in 2008 to date.

As per the IMS data regarding the global anticoagulant market, warfarin use has declined from 87,5\% to $72 \%$ through 2008 to 2014. In contrast, NOACs have reached a market share of $15,5 \%$ as of 2014 (Fig. 1).

Fig. 1 presents the standard units (number of tablets the patients receive) data of 2014 showing a 1.35-fold higher usage rate for Factor Xa inhibitors compared to direct thrombin inhibitors. Standard units show that rivaroxaban as the most commonly preferred agent among Factor Xa inhibitors as of 2014.

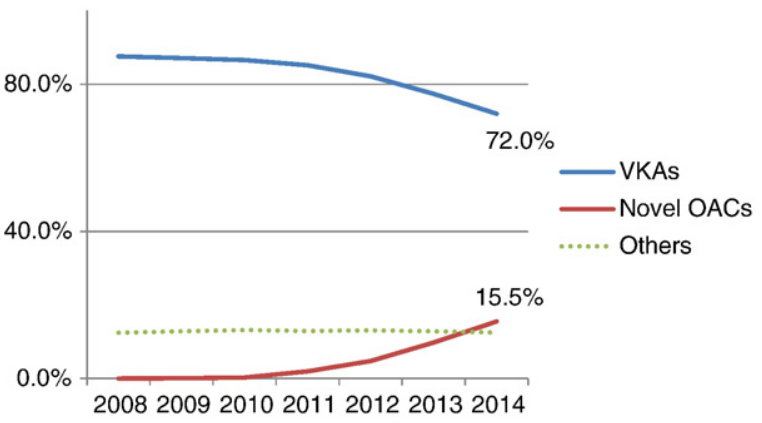

Fig. 1. Global AC Market Volume Shares in \% (based on DoT*). Source: IMS MIDAS, Database: Current All 2014. *DoT = days of therapy, calculated based on volume in SU (standard units). For dabigatran and apixaban: DOT $=$ SU divided by 2 (assumption: two tablets per day). For VKA, rivaroxaban: DOT = SU (assumption: 1 tablet per day).

\section{Conclusion}

The success of these NOAC drugs means that warfarin will eventually become redundant in patients with NVAF, VTE and pulmonary embolism. This might take several years. In stroke prevention, these drugs are major breakthrough and stroke prevention is much more important than which drug is better than the others. That is a question hard to answer and at the moment is based more on opinions than fact.

\section{Disclosure statement}

The authors have no financial support or conflicts of interest to disclose.

\section{References}

1. De Caterina R. The current role of anticoagulants in cardiovascular medicine. $J$ Cardiovasc Med (Hagerstown) 2009;10:595-604.

2. Geerts WH, Bergqvist D, Pineo GF, Heit JA, Samama CM, Lassen MR, et al. Prevention of venous thromboembolism: American College of Chest Physicians Evidence-Based Clinical Practice Guidelines (8th Edition). Chest 2008;133(6 Suppl):381S-453S.

3. Kearon C, Kahn SR, Agnelli G, Goldhaber S, Raskob GE, Comerota AJ, American College of Chest Physicians. Antithrombotic therapy for venous thromboembolic disease: American College of Chest Physicians Evidence-Based Clinical Practice Guidelines (8th Edition). Chest 2008;133(6 Suppl):454S-545S.

4. Wolf PA, Abbott RD, Kannel WB. Atrial fibrillation as an independent risk factor for stroke: the Framingham Study. Stroke 1991;22:983-988.

5. Britton M, Gustafsson C. Non-rheumatic atrial fibrillation as a risk factor for stroke. Stroke 1985;16:182-188.

6. Bogousslavsky J, Van Melle G, Regli F, Kappenberger L. Pathogenesis of anterior circulation stroke in patients with nonvalvular atrial fibrillation: the Lausanne Stroke Registry. Neurology 1990;40:1046-1050.

7. Manning WJ, Silverman DI, Waksmonski CA, Oettgen P, Douglas PS. Prevalence of residual left atrial thrombi among patients with acute thromboembolism and newly recognized atrial fibrillation. Arch Intern Med 1995;155:2193-2198.

8. Longstreth Jr WT, Bernick C, Fitzpatrick A, et al. Frequency and predictors of stroke death in 5,888 participants in the Cardiovascular Health Study. Neurology 2001;56: 368-375.

9. Goldhaber SZ. Pulmonary embolism thrombolysis: a clarion call for international collaboration. J Am Coll Cardiol 1992;19:246-247.

10. Anderson Jr FA, Wheeler HB, Goldberg RJ, et al. A population-based perspective of the hospital incidence and case-fatality rates of deep vein thrombosis and pulmonary embolism. The Worcester DVT Study. Arch Intern Med 1991;151:933-938.

11. Heit JA, Fallon WM, Petterson TM, et al. Relative impact of risk factors for deep vein thrombosis and pulmonary embolism: a population-based study. Arch Intern Med 2002;162:1245-1248.

12. Lindblad B, Eriksson A, Bergqvist D. Autopsy-verified pulmonary embolism in a surgical department: analysis of the period from 1951 to 1988. Br J Surg 1991;78: 849-852.

13. Sandler DA, Martin JF. Autopsy proven pulmonary embolism in hospital patients: are we detecting enough deep vein thrombosis? J R Soc Med 1989;82:203-205.

14. The EINSTEIN Investigators. Oral Rivaroxaban for symptomatic venous thromboembolism. N Engl J Med 2010;363:2499-2510.

15. Albers GW, Yim JM, Belew KM, et al. Status of antithrombotic therapy for patients with atrial fibrillation in university hospitals. Arch Intern Med 1996;156:2311-2316.

16. Go AS, Hylek EM, Borowsky LH, Phillips KA, Selby JV, Singer DE. Warfarin use among ambulatory patients with nonvalvular atrial fibrillation: the anticoagulation and risk factors in atrial fibrillation (ATRIA) study. Ann Intern Med 1999;131:927-934. 
17. Piccini JP, Hernandez AF, Zhao X, et al. Quality of care for atrial fibrillation among patients hospitalized for heart failure. J Am Coll Cardiol 2009;54:1280-1289.

18. Hanley CM, Kowey PR. Are the novel anticoagulants better than warfarin for patients with atrial fibrillation? J Thorac Dis 2015;7 (165-7.1)

19. De Caterina R, Husted S, Wallentin L, European Society of Cardiology working group on thrombosis task force on anticoagulants in heart disease, et al. General mechanisms of coagulation and targets of anticoagulants (section I). Position paper of the ESC Working Group on Thrombosis-Task Force on Anticoagulants in Heart Disease. Thromb Haemost 2013;109:569-579.

20. Mozaffarian D, Benjamin EJ, Go AS, Arnett DK, Blaha MJ, Cushman M, et al. Heart disease and stroke statistics-2015 update: a report from the American Heart Association. Circulation 2015;131:e29-e322.

21. Halperin JL, Hart RG. Atrial fibrillation and stroke: new ideas, persisting dilemmas. Stroke 1988;19:937-941.

22. Connolly SJ, Ezekowitz MD, Yusuf S, et al. Dabigatran versus warfarin in patients with atrial fibrillation. N Engl J Med 2009;361:1139-1151.

23. Granger CB, Alexander JH, McMurray JJ, et al. Apixaban versus warfarin in patients with atrial fibrillation. N Engl J Med 2011;365:981-992.

24. Patel MR, Mahaffey KW, Garg J, et al. Rivaroxaban versus warfarin in nonvalvular atrial fibrillation. N Engl J Med 2011;365:883-891.
25. Ruff CT, Guigliano RP. Comparison of the efficacy and safety of new oral anticoagulants with warfarin in patients with atrial fibrillation: a meta-analysis of randomised trials. Lancet Mar 15 2014;383:955-962.

26. Camm AJ, Lip GY, et al. 2012 focused update of the ESC Guidelines for the management of atrial fibrillation: an update of the 2010 ESC guidelines for the management of atrial fibrillation developed with the special contribution of the European Heart Rhythm Association. Europace 2012;14:1385-1413.

27. IMS MIDAS Database. http://www.imshealth.com/portal/site/imshealth 2014

28. Taylor TN, Davis PH, Torner JC, Holmes J, Meyer JW, Jacobson MF. Lifetime cost of stroke in the United States. Stroke 1996;27:1459-1466.

29. Roger VL, Go AS, Lloyd-Jones DM, Benjamin EJ, Berry JD, Borden WB, American Heart Association Statistics Committee and Stroke Statistics Subcommittee, et al. Heart disease and stroke statistics-2012 update: a report from the American Heart Association. Circulation 2012;125:e2-e220.

30. Harrington AR, Armstrong EP, Nolan Jr PE, Malone DC. Cost-effectiveness of apixaban, dabigatran, rivaroxaban, and warfarin for stroke prevention in atrial fibrillation. Stroke 2013;44:1676-1681. 